\title{
Hypermobility in Adolescent Females: Prevalence Data from India and Europe
}

\section{Poonam Dhankher ${ }^{1}$, Joginder Singh Yadav² and Ashish Devgan ${ }^{3}$}

\author{
${ }^{1}$ PhD Scholar, SGT University, Budhera, Gurugram., Assistant Professor, College of Physiotherapy \\ Pt.B.D.S, University of Health Sciences, Rohtak, Haryana 124001 (INDIA).
}

2Professor, Faculty of Physiotherapy, SGT University, Budhera, Gurugram.

${ }^{3}$ Senior Professor, Department of Orthopedics, PGIMS, Rohtak.

E- mail: poonam.dhankher.jhajhria@gmail.com; jogiyadav2@gmail.com

*Corresponding author: Poonam Dhankher; poonam.dhankher.jhajhria@gmail.com

\begin{abstract}
The joint hypermobility syndrome is a condition that features joints that easily move beyond the normal range expected for that particular joint. People of all races and age groups are affected by joint hypermobility. The aim of the current study was to compare age and sex specific estimates of the prevalence of hypermobility derived from studies in India and Europe. GJH was assessed using a cut off Beighton score greater than 4/9. Joint hypermobility was found to be higher in both school going adolescent females and elite level athletes in the Indian population as compared to the same groups in European population.
\end{abstract}

Keywords: hypermobility; beighton score; India; Europe

\section{BACKGROUND}

Joint hypermobility arises due to laxity in the ligaments [1] and can occur in concurrence with disorders affecting collagen. The joint hypermobility syndrome is a condition that features joints that easily move beyond the normal range expected for that particular joint. In a large number of cases hypermobility presents as an isolated finding. Hypermobility syndrome has been defined as a generalised joint laxity with associated musculoskeletal complaints in the absence of any rheumatic disease.[2]

To estimate about the magnitude of this problem, many studies aimed at finding the prevalence of hypermobility have been conducted throughout the world: in Europe [3,4,5,6], Middle East [7,8,9], United States of America [10,11] and India $[12,13,14]$. These studies present varied sources of data example questionnaires, reviews etc, data collection methods, targeted age groups and population. The current literature reports that the prevalence of generalised joint laxity in the age group 6-15 years varies between 8.8\% [15] to 64.6\% [16]. Prevalence within the schoolchildren aged 14 years, generalised joint hypermobility (cut off point, $4 / 9$ ) has been reported to be between $11 \%$ to $28 \%$ [3]. Epidemiological studies suggest that people of all races and age groups are affected by generalised joint hypermobility. The prevalence is more in children and adolescents, who tend to possess greater mobility of joints [17]. Ten to twenty percent of all people tend to have hypermobility, particularly children, adolescents and in the female sex. Also, it has been shown to be more prevalent in Asians and west Africans [18]. Asian Indians have been found to be more mobile than English Caucasians. Hand flexibility is also more in Asians than Caucasians [19].

The degree of hypermobility can be assessed and documented by the Beighton Score, which incorporates 5 simple manoeuvres four passive bilateral and one active unilateral performance to calculate a score between 0 and 9 (FIGURE 1)

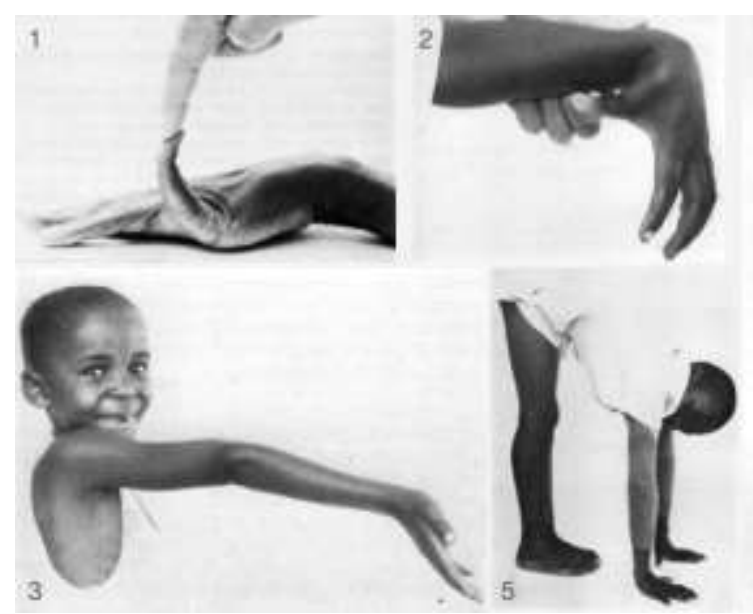

FIGURE 1

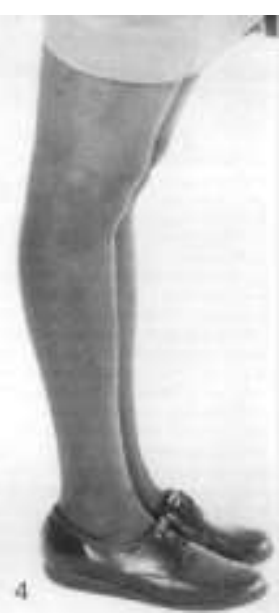


AIM:

The aim of the current study was to compare age and sex specific estimates of the prevalence of hypermobility derived from studies in India and Europe.

\section{METHODS:}

The operational definition of hypermobility as "Hypermobility syndrome (HMS) is a dominant inherited connective tissue disorder described as "generalized articular hypermobility, with or without subluxation or dislocation" was retained. The cut off score of Beighton's score was limited at 4/9.

\section{PREVALENCE DATA:}

\section{Studies from India:}

1) The data for prevalence of hypermobility was obtained from a study [20] done on children aged 12-15 years from Pimpri, Pune Hypermobility test for the joints was done and scores was calculated according to Beighton score protocol, with the cut-off value equal and more than 4, to consider a child as hypermobile. Recording of the data was done and a percentage analysis was done.

2) We obtained data for prevalence of hypermobility in adolescent females studying in schools of Haryana state, India. In the study 1827 adolescent females studying in schools of Haryana were examined for hypermobility with Beighton's score cut off taken as $4 / 9$ as reported in other studies.

3) The data from a study done on hockey players in Amritsar, India was obtained [21]. Total 188 (60 females, 128 males) hockey players were included in this study. The study population was obtained from local hockey teams and participants were school, university, national and international players. Each player was assessed for hypermobility using a validated Beighton scale.

\section{Studies from Europe:}

1) The prevalence of hypermobility in adolescent females in United Kingdom comes from a study done in 2012[3] in which a cross-sectional analysis of the subjects taken from Avon Longitudinal Study of Parents and Children (ALSPAC) was done. This study is based on 6022 children who attended the aged 14 research clinic and were assessed for hypermobility. Generalised joint laxity was assessed by trained measurers in the aged 14 research clinic using the modified Beighton nine-point scoring system as already described. Each joint was assessed separately. A cut-off of $\geq 4$ hypermobile joints was used, based on the most common cut-off cited in the literature.

2) The prevalence data of joint hypermobility in Denmark was obtained from a study [22] involving elite level adolescent female athletes aged 13 to 16 years, who participated in ballet, Team Gym gymnastics (noncontact sports), or team handball (contact sport). A total of 96 females were examined for hypermobility. The participants were tested to determine their Beighton score. Participants were classified GJH4 for a Beighton score of 4 or higher which we have taken as a cut off score for hypermobility.

3) The prevalence of hypermobility in Turkey was obtained from a study [9] on adolescent females in the age group of 13-19 years studying in high schools of turkey. A total of 433 adolescent females were examined for hypermobility using the Beighton's score and a cut off score of $4 / 9$ was used to evaluate hypermobility.

\section{RESULTS:}

1) In the prevalence study by Preeti et al of adolescent females aged 12-15 years from Pimpri, Pune, India, the prevalence was found to be $27.77 \%$.

2) Prevalence data obtained in the study by Poonam Dhankher et al from adolescent females aged 13-18 years studying in schools of Haryana was found to be $55.39 \%$. Out of the 1827 females examined for hypermobility, 1012 were hypermobile.

3) Results in the study by Dhyaneshwar Popat Chaudhari indicated that $56.6 \%$ female hockey players were hypermobile.

4) The prevalence of generalised joint laxity in the study by Clinch et al found this population of 6022 children aged 13.8 years was $19.2 \%$ hypermobile based on a cut-off of $\geq 4$ joints. Girls had a higher prevalence than boys $(27.5 \%$ vs $10.6 \%$, $\mathrm{P}<0.001)$

5) The prevalence of GJH in the study by Schmidt et al in elite-level adolescent athletes was $34.37 \%$. 33 out of the total 96 girls tested positive for hypermobility criteria GJH4.

6) The prevalence of hypermobility in the high school students by Seckin et al examined from schools of Turkey was found to be $16.2 \%$ in this population. Out of 433 females, 70 females were found to be hypermobile when using cut off scores of 4/9 of the accepted Beighton's score.

\section{DISCUSSION:}

Joint hypermobility has been commonly observed in normal school children. The prevalence of GJH varies according to sex, age and race. Janssons et al. [24] reported that people of female sex exhibited a higher degree of general joint laxity than male sex at all ages. This finding was explained by hormonal changes. Joint hypermobility was found to be higher in both school going adolescent females and elite level athletes in the Indian population as compared to the same groups in European population.

Influence of ethnic background on GJH has been demonstrated by early researchers; specifically, a high prevalence of GJH has been found to be prevalent in Asian and African populations compared to the population in western countries. The comparison in prevalence rates between Studies in Europe and India are in concurrence with the above mentioned studies. 


\section{CONCLUSION:}

Prevalence estimates of hypermobility for the adolescent females were higher in Indian population than European population.

\section{REFERENCES:}

[1] Bird HA. Joint hypermobility in children. Rheumatology (Oxford) 2005; 44:703-4

[2] Kirk JA, Ansell BM, Bywaters EGL: The hypermobility syndrome. Muscular complaints associated with general hypermobility, Ann Rheum Dis 26:419-425, 1967

[3] Clinch J, Deere K, Sayers A, Palmer S, Riddoch C, Tobias JH, Clark EM:Epidemiology of generalized joint laxity (hypermobility) in fourteen-year-old children from the UK: a population-based evaluation. Arthritis \& Rheumatism 2011, 63:2819-2827.

[4] Smith et al. (2005) Smith R, Damodaran AK, Swaminathan S, Campbell R, Barnsley L. Hypermobility and sports injuries in junior netball players. British Journal of Sports Medicine. 2005;39(9):628-631. doi: 10.1136/bjsm.2004.015271.

[5] Decoster et al. (1997) Decoster LC, Vailas JC, Lindsay RH, Williams GR. Prevalence and features of joint hypermobility among adolescent athletes. Archives of Pediatrics \& Adolescent Medicine. 1997;151(10):989-992. doi: 10.1001/archpedi.1997.02170470023005.

[6] Hakim, Malfait \& Paepe (2010) Hakim AJ, Malfait F, Paepe A. The heritable disorders of connective tissue: epidemiology, nosology and clinical features. In: Hakim AJ, Keer R, Grahame R, editors. Hypermobility, Fibromyalgia and Chronic Pain. Edinburgh: Churchill Livingstone/Elsevier; 2010. pp. 3-17.

[7] Al-Rawi, Al-Aszawi \& Al-Chalabi (1985) Al-Rawi ZS, Al-Aszawi AJ, Al-Chalabi T. Joint mobility among university students in Iraq. British Journal of Rheumatology. 1985;24(4):326-331. doi: 10.1093/rheumatology/24.4.326

[8] Prevalence of joint hypermobility in Kuwait. Al-Jarallah K, Shehab D, Al-Jaser MT, Al-Azemi KM, Wais FF, Al-Saleh AM, Al-Ajmi AS, Al-Omairah HA, Abraham M, Sharma PN.Int J Rheum Dis. 2017 Aug;20(8):935-940. doi: 10.1111/1756185X.12556. Epub 2014 Dec 20.

[9] Seçkin et al. (2004) Seçkin Ü, Tur BS, Yılmaz Ö, Yağcı I, Bodur H, Arasil T. The prevalence of joint hypermobility among high school students. Rheumatology International. 2004; 25:260-263.

[10] Morris et al. (2017) Morris SL, O'Sullivan PB, Murray KJ, Bear N, Hands B, Smith AJ. Hypermobility and musculoskeletal pain in adolescents. Journal of Pediatrics. 2017; 181:213-221. doi: 10.1016/j.jpeds.2016.09.060.

[11] Arroyo, Brewer \& Giannini (1988) Arroyo IL, Brewer EJ, Giannini EH. Arthritis/arthralgia and hypermobility of the joints of schoolchildren. Journal of Rheumatology. 1988; 15:978-980.

[12] Hasija, Khubchandani \& Shenoi (2008) Hasija RP, Khubchandani RP, Shenoi S. Joint hypermobility in Indian children. Clinical and Experimental Rheumatology. 2008; 26:146-150.

[13] Abujam B, Aggarwal A. Hypermobility is related with musculoskeletal pain in Indian school-children. Clin Exp Rheumatol. 2014; 32:610-3.

[14] Subramanyam V. Janaki KV joint hypermobility in south Indian children. Indian Pediatr. 1996; 33:771-2.

[15] Vougiouka 0, Moustaki M, Tsanaktsi M. Benign hypermobility syndrome in Greek schoolchildren. European Journal of Pediatrics. 2000;159(8):628

[16] Lamari NM, Chueire AG, Cordeiro JA. Analysis of joint mobility patterns among preschool children. Sao Paulo Medical Journal. 2005;123(3):119-123.

[17] Remvig L, Jensen DV, Ward RC. Epidemiology of general joint hypermobility and basis for the proposed criteria for benign joint hypermobility syndrome: review of the literature. J Rheumatol. 2007;34(4):804-809.

[18] Hakim A J, Cherkas L F, Grahame R, et al. The genetic epidemiology of joint hypermobility: a population study of female twins. Arthritis Rheum. 2004;50(8):2640-2644.

[19] Shahid M. Mahroof S. Wu F. Bourne K. Jose R. Titley G. Are Asian hands more flexible than their Caucasian counterparts?.Hand Ther. 2013; 18: 71-76

[20] Preeti Gazbare, Priyanka Chavan. Prevalence of hypermobility in children aged 6-14-year World Journal Of Pharmaceutical Research volume 7 issue 8 649-655.

[21] Dnyaneshwar Popat Chaudhari, Shyamal Koley, J.S. Sandhu. Generalized Hypermobility and Its Relation to Injuries in Hockey Player Indian Journal of Physiotherapy and Occupational Therapy 
[22] Heidi Schmidt, Trine Lykke Pedersen, Tina Junge,Raoul Engelbert, Birgit Juul-Kristensen. Hypermobility in Adolescent Athletes: Pain, Functional Ability, Quality of Life, and Musculoskeletal Injuries journal of orthopaedic \& sports physical therapy 792 | October 2017 | volume 47 | number 10.

[23] Beighton P, de Paepe A, Danks D, et al. International Nosology of Heritable Disorders of Connective Tissue, Berlin, 1986. Am J Med Genet. 1988; 29: 581 - 594.

[24] Jansson A, Saartok T, Werner S, Renström P. General joint laxity in 1845 Swedish school children of different ages: age- and gender-specific distributions. Acta Paediatr 2004; 93:1202-6. 